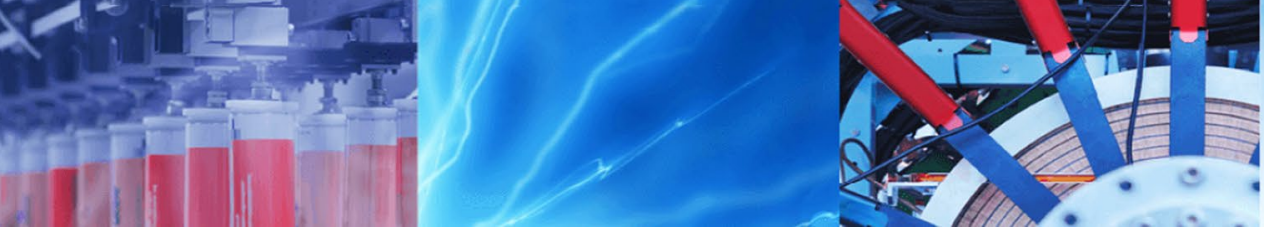

Research Article

\title{
Efficient removal of tetracycline hydrochloride from aqueous solution by mesoporous cage MOF-818
}

\author{
Zhiming Zhang ${ }^{1,2} \cdot$ Chenghan Ding ${ }^{1} \cdot$ Yuan $\mathrm{Li}^{1} \cdot$ Hanzhong Ke ${ }^{1} \cdot$ Guoe Cheng ${ }^{1,2} \mathbb{D}$
}

Received: 6 December 2019 / Accepted: 12 March 2020 / Published online: 16 March 2020

(c) Springer Nature Switzerland AG 2020

\begin{abstract}
MOF-818, a mesoporous cage metal-organic framework, was investigated for the removal of tetracycline hydrochloride (TC) from aqueous environment. The product was characterized by XRD, BET, FESEM, FT-IR, XPS and TGA. The influence of different parameters such as solution $\mathrm{pH}$, contact time, temperature, adsorption dosage, initial TC concentration on the adsorption capacity was investigated. The as-prepared MOF-818 showed rapid removal of TC and with maximum saturated adsorption capacity calculated to be $442.5 \mathrm{mg} \mathrm{g}^{-1}$ at pH 3.32, $323 \mathrm{~K}$. The adsorption isotherms were fitted by Langmuir, and Freundlich models. The kinetic data was analyzed by pseudo-first-order, pseudo-second-order, and intraparticle diffusion models. The TC adsorption process followed pseudo-second-order kinetics and best fitted the Langmuir adsorption model. The thermodynamic data showed that the adsorption was a spontaneous and endothermic reaction. A mechanism for TC adsorption was proposed and the chemisorption and $\pi-\pi$ interaction was believed to direct the interaction between MOF-818 and TC molecules.
\end{abstract}

Keywords Metal-organic frameworks · MOF-818 · Mesoporous cage $\cdot$ Tetracycline hydrochloride $\cdot$ Adsorption

\section{Introduction}

Nowadays, pollution in aquatic environments caused by discharge of toxic pollutants is a severe problem faced by numerous countries all around the world. Among the industrial pollutants, heavy metal ions such as $\mathrm{Cr}(\mathrm{VI})$, $\mathrm{As}(\mathrm{V}), \mathrm{Pb}^{2+}$ and $\mathrm{Hg}^{2+}[1-7]$ and organic pollutants including dyes [8-12] and antibiotics [13-15] are particularly prominent because all of them create a serious hazard to the aquatic system and human health even at low concentration. Therefore, from an environmental and safety perception, the removal of these types of toxic pollutants from wastewater is an important research topic. Several treatment methods such as adsorption [1-6, 8-10], ionexchange [7], photocatalytic degradation $[12,16,17]$, and biodegradation [18] have been developed for the removal of pollutants from wastewater. Among them, adsorption is highly regarded as a feasible, economical, and environmentally friendly approach for pollutants removal. Sorbents based on diverse materials such as nanocomposite, activated carbon, waste biomass, clay minerals etc. have been proved to be efficient for the removal of heavy metal ions, dyes and antibiotics.

Here, we focus on the removal of antibiotic Tetracycline hydrochloride (TC) from water environment by adsorption strategy. Antibiotic residues in aquatic ecosystem have always been serious environmental issues. $\mathrm{TC}$ is one of the most frequently used antibiotics which has been used to treat bacterial infections in humans and feed animals as a growth promoter. However, the lower utilization rate causes that more than $70 \%$ of tetracycline would be excreted in urine and feces of humans and

Guoe Cheng, chengge@cug.edu.cn | ${ }^{1}$ Faculty of Materials Science and Chemistry, China University of Geosciences (Wuhan), 388 Lumo Road, Wuhan 430074, China. ${ }^{2}$ Engineering Research Center of Nano-Geo Materials of Ministry of Education, China University of Geosciences (Wuhan), 388 Lumo Road, Wuhan 430074, China. 
animals and released into the environment [15]. As far as we know, various adsorption materials have been developed to remove TC from aqueous solution, such as clay minerals [19-21], zeolites composites [22, 23], graphene oxide (GO) [24], multi-walled carbon nanotubes (MWCNTs) [25], biochar [26-30], covalent-organic frameworks (COFs) [31], metal-organic frameworks (MOFs) [32-36] and their composites [37-41]. Among these adsorbent materials, MOFs, composed of organic linkers and metallic clusters, are a new class of porous materials. In comparison, MOFs have chemical and thermal stability, ease of structural functionalization, large specific surface area, and high porosity. More importantly, the pore sizes can be controlled and affinities toward pollute molecules including coordination bond, $\pi-\pi$ interactions, hydrogen bonding and electrostatic interactions can also be designed on purpose [42-45]. Therefore, MOFs have been identified as one of the most efficient adsorbents. For instance, according to the previous reports [46-48], the pore diameter of adsorbents should be 1.7 times larger than the adsorbate molecule's second-widest dimension, which would ensure that the target molecules could be effectively adsorbed because of size exclusion effect. Therefore, the design of MOFs with both special pore feature matching with the size of pollutant molecule and adsorption sites should be important to increase the adsorption capacity of organic pollutants. Tetracycline shows a basic structure composed of a tetracyclic naphthacene carboxamide ring system (Fig. 1). The ring structure of tetracycline is surrounded by various chemical functional groups and substituents, including $-\mathrm{OH},-\mathrm{CO}-, \mathrm{CONH}_{2},-\mathrm{CH}_{3},-\mathrm{N}\left(\mathrm{CH}_{3}\right)_{2}$. The TC molecules show the simulated size of $14.8 \times 9.00 \times 7.47 \AA$ and the pore sizes smaller than $15 \AA$ would be inaccessible for TC molecules [49]. Chen et al. [35] successfully synthesized hierarchical porous ZIF-8 with larger pores $(>2 \mathrm{~nm}$ ) in microporous MOFs and found it showed larger adsorption capacity. The expansion of pore size would help the diffusion of TC molecules in the pores and the exposure of more active sites. However, the synthesis of MOF materials with large-size mesoporous channels is still a challenge.

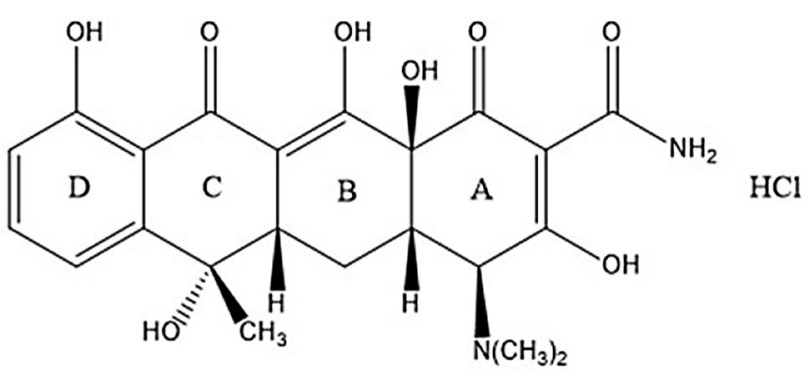

Fig. 1 The chemical structure of tetracycline hydrochloride (TC)
MOF-818, a new kind of MOF structure with mesoporous cages of unprecedented polyhedra, was reported by H. Deng group in 2018 [50]. The mesoporous cage with the diameter of $3.8 \mathrm{~nm}$ is big enough for inclusion of the large size dimensions biomolecules vitamin$B_{12}$ and insulin. Furthermore, it exhibits excellent chemical stabilities in air and in water with a wide $\mathrm{pH}$ range $(\mathrm{pH}=2-12)$. However, the research on its application has not been expanded yet. In this work, we systematically studied the adsorption of tetracycline on MOF-818. The asprepared MOF- 818 shows rapid removal with the adsorption capacity of $442.5 \mathrm{mg} \mathrm{g}^{-1}$, which is larger than those by other unmodified MOFs reported previously.

\section{Materials and methods}

\subsection{Materials and chemicals}

Copper(II) nitrate trihydrate $\left(\mathrm{Cu}\left(\mathrm{NO}_{3}\right)_{2} \cdot 3 \mathrm{H}_{2} \mathrm{O}\right)$, Zirconyl(IV) chloride octahydrate $\left(\mathrm{ZrOCl}_{2} \cdot 8 \mathrm{H}_{2} \mathrm{O}\right), 1 \mathrm{H}$-pyrazole-4-carboxylic acid $\left(\mathrm{H}_{2} \mathrm{PyC}\right)$, trifluoroacetic acid (TFA), N,N-dimethylformamide (DMF), Tetracycline hydrochloride (TC) were purchased from Sinopharm Chemical Reagent Co., Ltd. All chemicals were used without further purifications.

\subsection{Synthesis of MOF-818.}

MOF-818 was synthesized according to the literature [50] with modification. $\mathrm{ZrOCl}_{2} \cdot 8 \mathrm{H}_{2} \mathrm{O}(212.5 \mathrm{mg}, 0.659 \mathrm{mmol})$, $\mathrm{Cu}\left(\mathrm{NO}_{3}\right)_{2} \cdot 3 \mathrm{H}_{2} \mathrm{O}(620.0 \mathrm{mg}, 2.57 \mathrm{mmol})$, trifluoroacetic acid $(600 \mu \mathrm{L})$ and $\mathrm{H}_{2} \mathrm{PyC}(162.5 \mathrm{mg}, 1.45 \mathrm{mmol})$ were dissolved in $50 \mathrm{~mL}$ of DMF by ultrasonic in a $100 \mathrm{~mL}$ beaker. The mixture was then transferred to a $100 \mathrm{~mL}$ teflon-lined stainless steel reactor and heated at $100{ }^{\circ} \mathrm{C}$ for $10 \mathrm{~h}$. The as-synthesized blue crystal was immersed into DMF for 3 days, during which the DMF solvent was exchanged for five times. The solvent exchange with acetone was performed through Soxhlet extraction for 2 days. The obtained MOF818 sample was dried in vacuum at $150^{\circ} \mathrm{C}$ for $12 \mathrm{~h}$ and filled with $\mathrm{N}_{2}$ for storage.

\subsection{Batch experiments}

The adsorption of TC from aqueous solutions was performed by batch experiments. The effects of solution $\mathrm{pH}$, contact time, temperature, adsorption dosage, and initial TC concentration on adsorption were investigated, respectively. All adsorption experiments were carried out in $50 \mathrm{~mL}$ glass flask with $20 \mathrm{~mL}$ TC solution containing MOF-818. The initial $\mathrm{pH}$ of solution was adjusted with $0.1 \mathrm{~mol} \mathrm{~L}^{-1} \mathrm{NaOH}$ solution. The suspension was magnetically stirred at $500 \mathrm{rpm}$ at certain temperature. The mixed 
solution was filtered through a $0.22 \mu \mathrm{m}$ membrane filter at predetermined time intervals and the residual TC concentration was determined spectrophotometically at $256 \mathrm{~nm}$.

The adsorption amount of TC onto adsorbent at a predetermined time was calculated according to Eq. 1:

$q_{t}=\left(C_{0}-C_{t}\right) V / m$

The removal efficiency $(r)$ is calculated via Eq. 2:

$r=\left(C_{0}-C_{t}\right) / C_{0}$

where $q_{t}\left(\mathrm{mg} \mathrm{g}^{-1}\right)$ is the adsorption amount of MOF-818 at time $t(\mathrm{~min}), C_{0}\left(\mathrm{mg} \mathrm{L}^{-1}\right)$ and $C_{t}\left(\mathrm{mg} \mathrm{L}^{-1}\right)$ are respectively the concentration of TC at initial and time $t(\mathrm{~min}), V(\mathrm{~L})$ is the solution volume and $m(\mathrm{~g})$ is the mass of adsorbent MOF-818.

\subsection{Characterization}

Powder X-ray diffraction (PXRD) patterns were taken on a Bruker D8 Advance diffractometer from $2 \theta=1^{\circ}$ to $10^{\circ}$ operated at $45 \mathrm{kV}, 200 \mathrm{~mA}$ for $\mathrm{Cu} \mathrm{Ka}(\lambda=1.5406 \AA)$ with a scan speed of $1^{\circ}$ per second and a step size of $0.01^{\circ}$. Scanning electron microscope (SEM) was carried out on a SU8010 model Hitachi microscope. FT-IR spectra were measured from 400 to $4000 \mathrm{~cm}^{-1}$ by Nicolet iS50 FT-IR spectrometer. Thermogravimetric analysis (TGA) was performed on a NETZSCH STA 409 PC thermogravimeter from 30 to $800{ }^{\circ} \mathrm{C}$ at the heating rate of $10^{\circ} \mathrm{C} \cdot \mathrm{min}^{-1}$ under $\mathrm{N}_{2}$ atmosphere. Nitrogen adsorption/desorption isotherms were measured at $77 \mathrm{~K}$ with Micromeritics ASAP2460. The UV-Vis absorption spectra were recorded on Shimadzu UV-2501PC UV-Vis spectrophotometer. Specific elemental surface contents and their valence state were measured with X-ray photoelectron spectroscopy (XPS, Thermo ESCALAB 250XI, USA).

\section{Results and discussion}

\subsection{Characterizations}

The PXRD measurements were employed to examine the crystalline phase of the MOF-818. As shown in Fig. 2a, the data showed an intense peak at $3.09^{\circ}$ and five other peaks at $4.96^{\circ}, 5.80^{\circ}, 6.05^{\circ}, 7.00^{\circ}$ and $7.60^{\circ}$, which were indexed to the (111), (220), (311), (222), (400) and (331) diffractions, respectively. The diffraction peaks of MOF-818 matched well with the simulated one in the literature [50]. No peaks corresponding to $\mathrm{CuO}$ or $\mathrm{ZrO}_{2}$ were found. Therefore, the XRD results confirmed the formation of pure MOF- 818 crystal.

The $\mathrm{N}_{2}$ adsorption/desorption isotherm of MOF- 818 was estimated at $77 \mathrm{~K}$ and the results are presented in Fig. $2 \mathrm{~b}$. It can be seen that the obtained MOF-818 samples demonstrated a good nitrogen uptake at the relative pressure $\mathrm{P} / \mathrm{P}_{0}<0.3$ and the nitrogen isotherms were corresponded to type IV, which proves the existence of mesopores in the samples. The mesopore diameter calculated by density functional theory (DFT) method was mostly concentrated at $2.95 \mathrm{~nm}$, which was slightly lower than the theoretical value of $3.1 \mathrm{~nm}$ calculated by the analysis of crystal structure [50]. A small part of the pore size distributed at $1.59 \mathrm{~nm}$ was also found. The Brunauer-Emmett-Teller (BET) specific surface area was calculated to be 1408 $\mathrm{m}^{2} \cdot \mathrm{g}^{-1}$ (Langmuir surface area was $1940 \mathrm{~m}^{2} \mathrm{~g}^{-1}$ ). These results further conformed the mesoporous structures of MOF-818 crystals with desired surface area.

Thermogravimetric study is useful in determining the thermal stability of MOF-818 sample. The TGA curve of MOF-818 is also presented in Fig. 2c. The weight loss about $4 \%$ below $200{ }^{\circ} \mathrm{C}$ could be attributed to the elimination of free water and guest molecules. The sharp weight loss about $29.3 \%$ occurred from 280 to $375^{\circ} \mathrm{C}$. It should be (a)

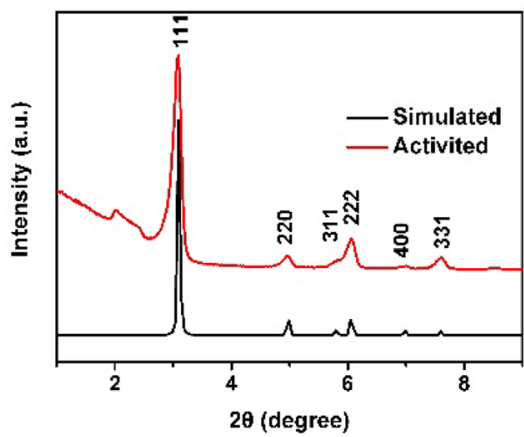

(b)

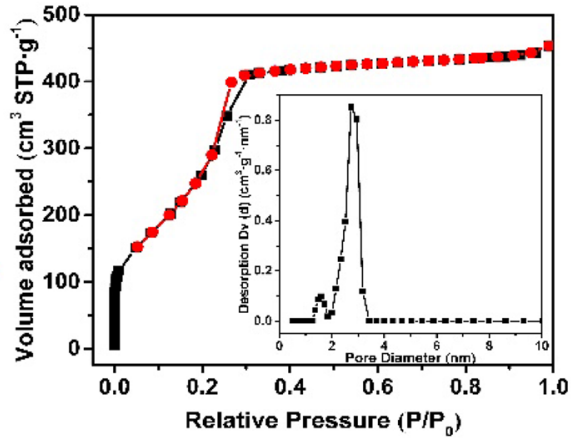

(c)

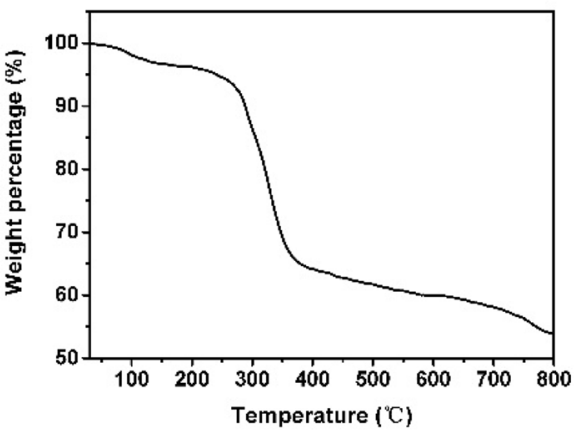

Fig. 2 a XRD patterns of as-synthesized MOF-818 and simulated MOF-818; $\mathbf{b}$ nitrogen adsorption-desorption isotherms at $77 \mathrm{~K}$ and pore size distribution (in set) of MOF-818. c TGA trace of MOF-818 
derived from the decomposition of $\mathrm{H}_{2} \mathrm{PyC}$ concerning the collapse of the MOF-818 framework. Therefore, it can be concluded that the MOF-818 showed good thermal stability below $280^{\circ} \mathrm{C}$, which is consistent with the previous reports [50].

The crystal morphologies of samples before (MOF-818 Fig. 3 a, b) and after TC absorption (TC-MOF-818, Fig. 3 c, d) were described using SEM images, respectively. It can be seen that the SEM images of MOF-818 before adsorption exhibited large-scale typical octahedral crystals with average particle size of about $250 \mathrm{~nm}$. More importantly, the typical octahedral crystal morphology of MOF-818 was well remained after adsorption.

\subsection{Batch experiments}

\subsubsection{Effect of $\mathrm{pH}$}

The change of $\mathrm{pH}$ value would affect the physiochemical properties of TC, thus influence the adsorptive interactions between TC and MOF-818. As we know, TC molecules can form three species under variation of $\mathrm{pH}$ values including cationic species $(\mathrm{pH}<3.3)$, zwitterionic species $(3.3<\mathrm{pH}<7.69)$ or anionic species $(\mathrm{pH}>7.69)$ [43]. In the $\mathrm{pH}$ range from 3.3 to 7.69 , TC molecules predominantly exists as neutral species with a small proportion of cationic species. With the solution alkalinity increased, composition of TC molecule would change and a monovalent anion or a divalent anion will prevail. Considering the different charges on different site depending on solution $\mathrm{pH}$, the adsorption kinetic of TC onto MOF-818 was investigated by varying the $\mathrm{pH}$ of 3.32 (TC original solution), 4, 5 and 6 at $303 \mathrm{~K}$, a dosage of $0.5 \mathrm{~g} \cdot \mathrm{L}^{-1}$ and initial TC concentration of $300 \mathrm{mg} \mathrm{L}^{-1}$. The removal efficiency of TC as a function of pH was shown in Fig. 4a. It can be seen that samples showed almost the same removal efficiency all the time at various $\mathrm{pH}$ values. The curves showed a very fast TC adsorption rate within the initial $25 \mathrm{~min}$. After around $60 \mathrm{~min}$, the curves reached a plateau, suggesting the adsorption reaction reached equilibrium. Overall, the removal efficiency of TC showed very low sensitivity to the $\mathrm{pH}$ variation in the range of 3.32-6. This result implied that the electrostatic interaction hadn't been involved in the process of TC uptake.
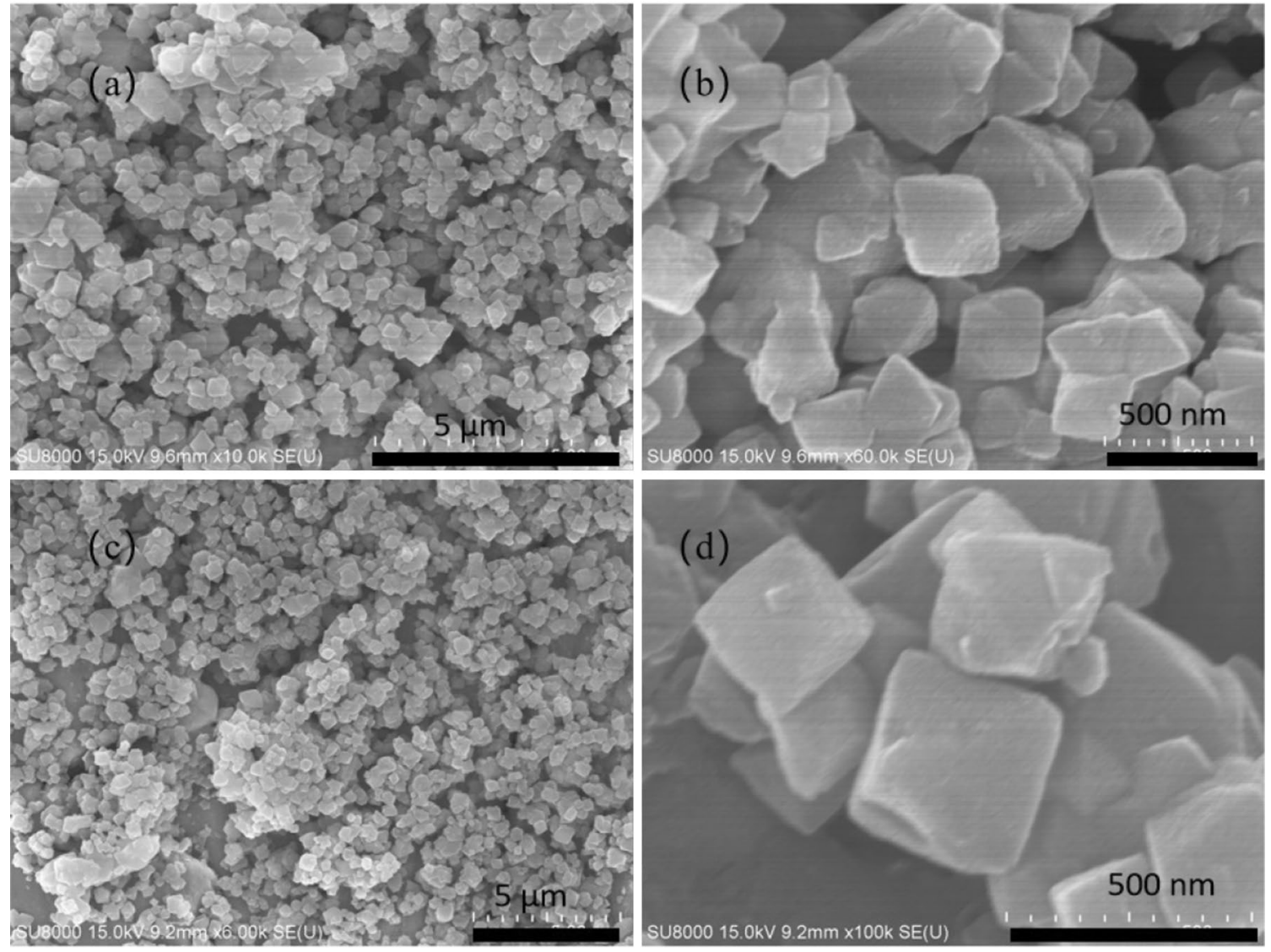

Fig. 3 SEM images of MOF-818 (a, b) and TC-MOF-818 (c, d)

SN Applied Sciences

A SPRINGER NATURE journal 
(a)

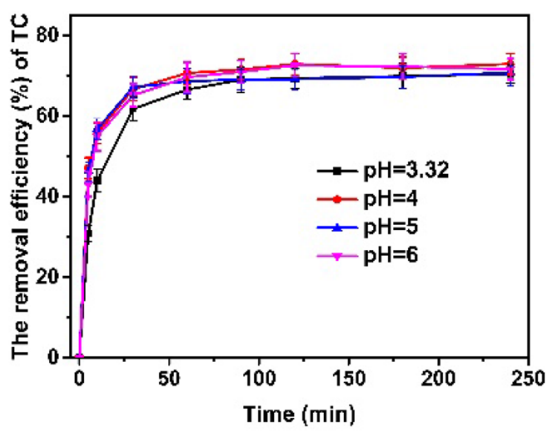

(b)

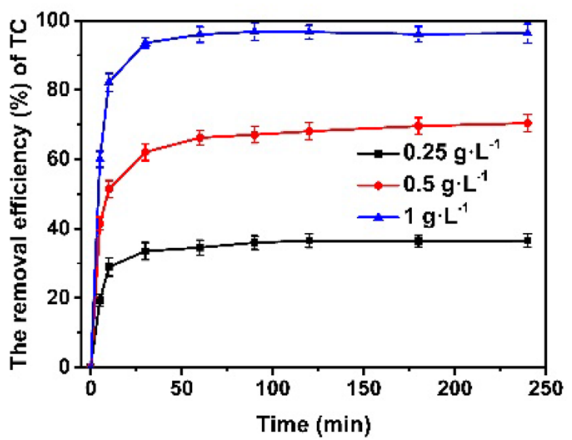

(c)

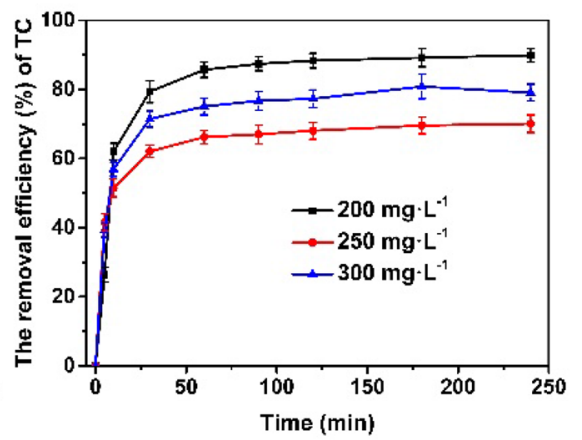

Fig. 4 Influence of various parameters on the TC adsorption at different $\mathbf{a} \mathrm{pH}$. $\mathbf{b}$ Adsorbent dosage and $\mathbf{c}$ initial TC concentration

\subsubsection{Effect of adsorption dosage}

The effect of MOF-818 dosages was studied for the adsorption of TC at $303 \mathrm{~K}, \mathrm{pH} 3.32$ and initial TC concentration of $300 \mathrm{mg} \mathrm{L}^{-1}$. As shown in Fig. 4b, the increased MOF-818 dosage resulted in a tremendous improvement in adsorption capacities. It can be ascribed to the more adsorption sites and pore volumes provided by MOF- 818 . When the amount of adsorbent was used to be $1 \mathrm{~g} \mathrm{~L}^{-1}$, the removal rate of TC reached as high as $96.27 \%$ at the initial TC concentration of $300 \mathrm{mg} \mathrm{L}^{-1}$.

\subsubsection{Effect of initial TC concentration}

The effect of initial TC concentration on the adsorption was investigated over a range of $200-300 \mathrm{mg} \mathrm{L}^{-1}$ at $303 \mathrm{~K}, \mathrm{pH}$ 3.32 and a dosage of $0.5 \mathrm{~g} \mathrm{~L}^{-1}$ (Fig. 4c). It was observed that the TC removal efficiency was decreased with the rise of initial TC concentration. With the initial TC concentrations of 200,250 and $300 \mathrm{mg} \mathrm{L}^{-1}$, the removal efficiencies at equilibrium were $89.91 \%, 79.09 \%$ and $70.39 \%$, respectively. The results suggested that MOF-818 didn't provide sufficient active sites for adsorption of the TC with the increased concentration. On the other hand, it showed efficient removal at lower initial concentration.

\subsection{Adsorption isotherms}

The adsorption isotherm is of great importance in assessing the maximum adsorption capacity and providing insight into the reaction mechanism. The adsorption isotherms of TC onto MOF-818 were studied at the temperatures of $293 \mathrm{~K}, 303 \mathrm{~K}, 313 \mathrm{~K}$ and $323 \mathrm{~K}$. As can be seen from Fig. $5 \mathrm{a}$ that the equilibrium adsorption amount $q_{e}$ was improved with the increase of initial concentration of TC solution. Meanwhile, temperature had a significant effect on TC adsorption behavior. The $q_{e}-c_{e}$ curve ascended as temperature increased, revealing that the adsorption of TC was an endothermic process. High temperature was favorable for the adsorption.

Langmuir and Freundlich isotherm models were employed to evaluate adsorption isotherm according to Eqs. 3 and 4, respectively.

$\frac{C_{e}}{q_{e}}=\frac{1}{q_{m} k_{L}}+\frac{C_{e}}{q_{m}}$

$\ln q_{e}=\ln k_{F}+\frac{1}{n} \ln C_{e}$

where $q_{e}\left(\mathrm{mg} \mathrm{g}^{-1}\right)$ is the equilibrium adsorption capacity, $C_{e}\left(\mathrm{mg} \mathrm{L}^{-1}\right)$ is the equilibrium concentration of TC, $q_{m}$ $\left(\mathrm{mg} \mathrm{g}^{-1}\right)$ is the theoretical maximum adsorption capacity, $k_{L}$ is the Langmuir equilibrium adsorption constant, $k_{F}$ and $n$ are Freundlich constants related to the sorption capacity and sorption intensity, respectively.

The isotherm parameters and the linear regression coefficients extracted from the experimental data are presented in Table 1. It can be seen that the theoretical saturated adsorption amount increased with temperature raised, which was consistent with the experimental data. The maximum theoretical saturated adsorption capacity at $323 \mathrm{~K}$ was $442.5 \mathrm{mg} \cdot \mathrm{g}^{-1}$, which is better than ZIF-8 [33] and biochar materials reported in the literatures $[26,27,30]$.

At different temperatures, the correlation coefficient $R^{2}$ values for the Langmuir model were much higher than that for Freundlich model. Moreover, the fitting curve of the Langmuir isotherm model exhibited better linearity than Freundlich isotherm model as shown in Fig. 5b, c. These results suggested that the Langmuir model could better represent the TC adsorption process. The adsorption of TC onto MOF-818 was dominated by monolayer adsorption and chemical adsorption might play the main role in the process of TC adsorption [44]. 
(a)
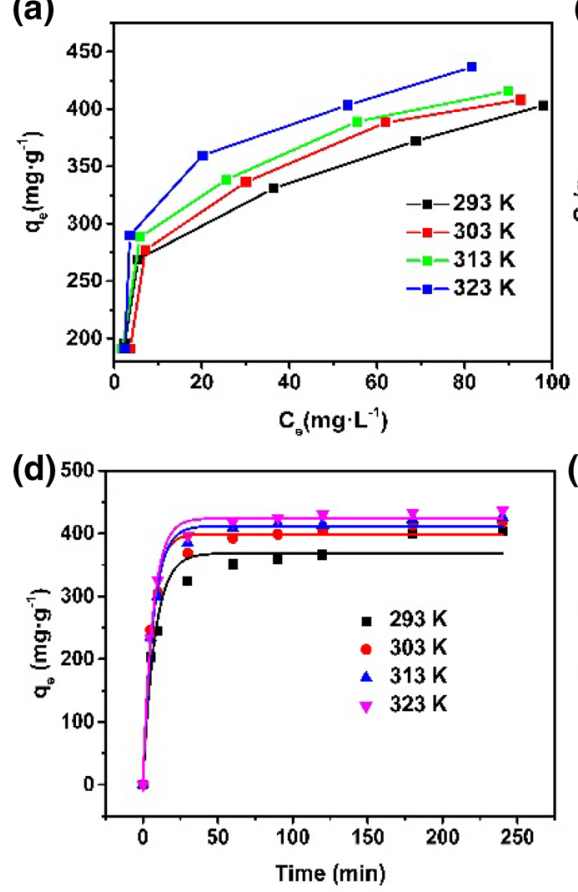

(b)

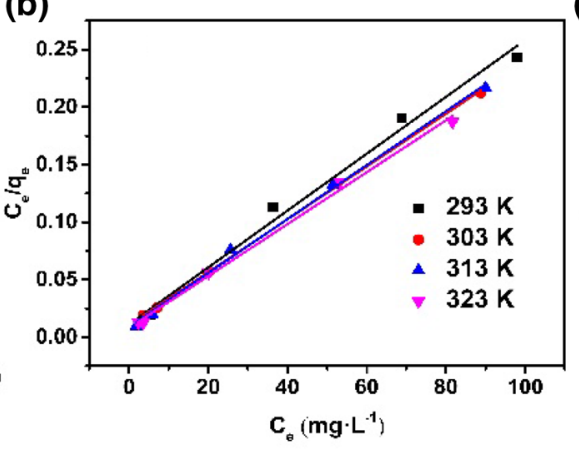

(e) 500

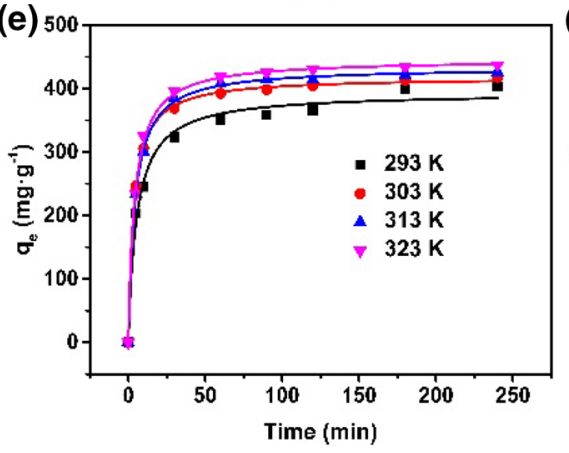

(c)

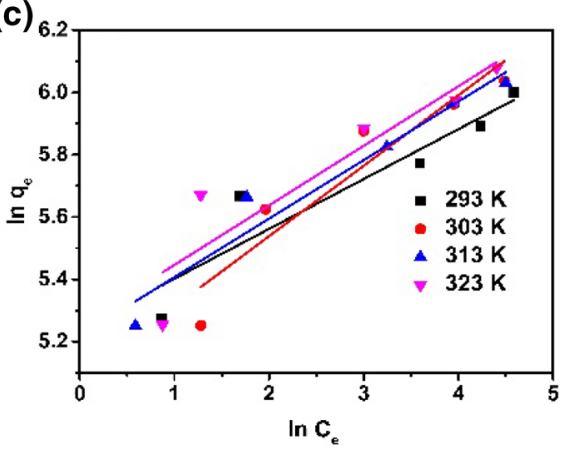

(f)

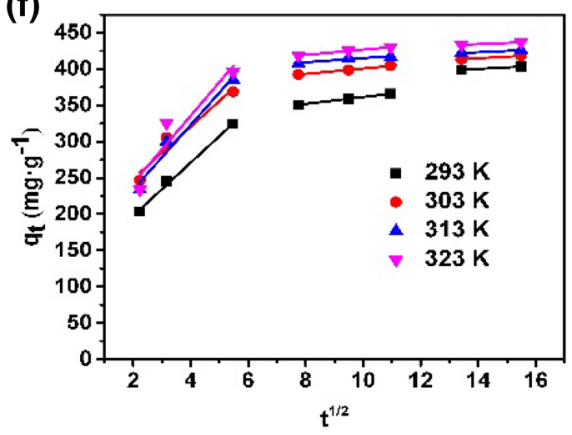

Fig. 5 Adsorption isotherms and Kinetics. a Adsorption isothermal curves, b Langmuir isotherm model and $\mathbf{c}$ Freundlich isotherm model. $\mathbf{d}$, e The fitting curves for the pseudo-first-order kinetic (d) and the pseudo-second-order kinetic (e). f Intra-particle diffusion model

Table 1 Linear fitting parameters for TC adsorption onto MOF- 818 by the Langmuir and Freundlich models

\begin{tabular}{|c|c|c|c|c|c|c|}
\hline \multirow[t]{2}{*}{$\mathrm{T}(\mathrm{K})$} & \multicolumn{3}{|c|}{ Langmuir model } & \multicolumn{3}{|c|}{ Freundlich model } \\
\hline & $\overline{K_{L}}$ & $q_{m}\left(\mathrm{mg} \mathrm{g}^{-1}\right)$ & $R_{L}^{2}$ & $1 / n$ & $K_{F}$ & $R_{F}^{2}$ \\
\hline 293 & 0.2201 & 404.9 & 0.9876 & 0.1602 & 189.0 & 0.8360 \\
\hline 303 & 0.2403 & 418.4 & 0.9996 & 0.2571 & 151.9 & 0.8412 \\
\hline 313 & 02.603 & 436.7 & 0.9972 & 0.1880 & 184.7 & 0.9303 \\
\hline 323 & 0.2821 & 442.5 & 0.9959 & 0.1912 & 191.5 & 0.8049 \\
\hline
\end{tabular}

\subsection{Kinetics analysis}

In order to further explore the adsorption behavior of TC on MOF-818, the pseudo-first-order and pseudo-secondorder kinetic models were used to study the adsorption kinetics of TC according to Eqs. 5 and 6, respectively.

pseudo-first-order kinetic model:

$$
\ln \left(q_{e}-q_{t}\right)=\ln q_{e}-k_{1} t
$$

pseudo-second-order kinetic model:

$$
\frac{t}{q_{t}}=\frac{t}{q_{e}}+\frac{1}{k_{2} q_{e}^{2}}
$$

where $q_{e}\left(\mathrm{mg} \mathrm{g}^{-1}\right)$ is the adsorption capacity at equilibrium; $q_{t}\left(\mathrm{mg} \mathrm{g}^{-1}\right)$ is the adsorption capacity at time $t$ $(\mathrm{min}) ; k_{1}\left(\mathrm{~min}^{-1}\right)$ is the rate constant of pseudo-first-order adsorption; $k_{2}\left(\mathrm{~g} \mathrm{mg}^{-1} \mathrm{~min}^{-1}\right)$ is the rate constant of pseudo-second-order adsorption.

Figure $5 \mathrm{~d}$, e shows the non-linear fitting kinetic curves of TC adsorption onto MOF-818. The kinetic parameters are summarized in Table 2 . As can be seen from Fig. $5 \mathrm{~d}$, e and Table 2, the pseudo-second-order kinetic model was more suitable for the experimental data with $R^{2}$ closer to 1 when compared with pseudo-first-order kinetic model. The adsorption capacities calculated by the pseudo-second-order kinetic model were much closer to experiment results. All these suggested that the adsorption process was much closely matched to the pseudo-second-order kinetic model, and the chemisorption might occur between adsorbates and adsorbents [51].

In order to explore the possible rate controlling adsorption process and the molecular diffusion mechanism, the intra-particle diffusion model was further applied to illustrate the experimental data (Fig. 5f). As shown in Fig. 5f, the 
Table 2 Nonlinear fitting kinetic parameters of TC adsorption on MOF-818

\begin{tabular}{llllllll}
\hline T (K) & \multicolumn{2}{l}{ Pseudo-first-order kinetic model } & & \multicolumn{3}{l}{ Pseudo-second-order kinetic model } \\
\cline { 2 - 3 } & $k_{1}\left(\mathrm{~min}^{-1}\right)$ & $q_{e}\left(\mathrm{mg} \mathrm{g}^{-1}\right)$ & $R^{2}$ & & $k_{2}$ & $q_{e}\left(\mathrm{~g} \mathrm{mg}^{-1} \mathrm{~min}^{-1}\right)$ & $R^{2}\left(\mathrm{mg} \mathrm{g}^{-1}\right)$ \\
\hline 293 & 0.12672 & 368.5 & 0.956 & & 0.0004608 & 393.46 & 0.988 \\
303 & 0.16865 & 398.9 & 0.983 & & 0.0006633 & 418.05 & 0.999 \\
313 & 0.14679 & 412.0 & 0.989 & & 0.0005378 & 433.69 & 0.999 \\
323 & 0.1514 & 424.1 & 0.9934 & & 0.0005388 & 446.07 & 0.998 \\
\hline
\end{tabular}

plots of $q_{t}$ against $t^{1 / 2}$ were composed of three linear sections, indicating that the TC adsorption processes were associated with three different stages. The first section was attributed to the transfer diffusion of TC molecules from solution to the surface of MOF- 818 crystals. This stage was controlled by the molecule diffusion and film diffusion. The second section was ascribed to the diffusion of the TC molecules from the outer surface into the internal pores of MOF-818. At this stage, the intra-particle diffusion was the rate limiting step, the steric effect had a significant influence on the adsorption rate. The third section implied the arrival of adsorption equilibrium. At the adsorption equilibrium stage, the TC molecules were adsorbed onto the active sites on the inner and outer surface of MOF-818. We also noted from Fig. $5 f$ that the regression lines of three stages didn't pass through the origin, conforming the involvement of outer diffusion. As a result, the overall adsorption process of TC onto MOF-818 involved outer diffusion and intra-partical diffusion [40,52].

\subsection{Thermodynamic studies}

The thermodynamic parameters of adsorption are obtained according to the adsorption isotherm parameter $K_{L}$ of Langmuir. The specific formulas are as follows.

$\Delta G=-R T \ln K_{L}$

$\ln K_{L}=\frac{\Delta S}{R}-\frac{\Delta H}{R T}$

where $R\left(8.314 \mathrm{~J} \mathrm{~mol}^{-1} \mathrm{~K}^{-1}\right), T(\mathrm{~K})$ and $K_{\mathrm{L}}\left(\mathrm{L} \mathrm{mol}^{-1}\right)$ represent the gas constant, adsorption temperature and the experimental Langmuir equilibrium constant, respectively.

The specific parameters of thermodynamics at different temperatures (293-323 K) were shown in Table 3. At different temperatures, the $\Delta G$ values were inversely linearly related to temperature, suggesting that increasing the temperature have a positive effect on adsorption throughout the adsorption system. At the same time, the $\Delta G$ values were all negative, which implied the adsorption was a spontaneous process in the standard state. It was also worth noting that all $\Delta G$ values were below $-20 \mathrm{~kJ} \cdot \mathrm{mol}^{-1}$, so the chemical interaction between molecules in the adsorption process was not excluded [38]. A positive value of $\Delta H$ indicates that the adsorption was an endothermic reaction, and the conclusion was consistent with the experimental results. Finally, the $\Delta S$ values can judge the degree of chaos in a system, according to the experimental calculation, the $\Delta S$ value was greater than 0 , suggesting that the system chaos increased after adsorption. This conclusion may be attributed to a certain degree of change in the surface structure of MOF-818 after binding to TC molecules [53].

\subsection{Proposed adsorption mechanism}

Based on the above analysis, we speculated various interactions would involve in the whole TC adsorption process. According to the influences of $\mathrm{pH}$ on TC adsorption, it was confirmed that the electrostatic force actually didn't exist over the range of $\mathrm{pH}=3.32-6$. However, the studies on adsorption kinetics, isotherms and thermodynamics revealed that the chemisorption might occur between adsorbates and adsorbents. To better understand the adsorption mechanism of TC by MOF-818, FT-IR spectrum and XPS analysis were employed to further illustrate the interactions between MOF-818 and TC molecules. As shown in Fig. 6, the distribution of characteristic FT-IR absorption peaks for MOF-818 and TC were in good agreement with the previous studies $[20,50]$. The infrared spectra in the range of $1200-1700 \mathrm{~cm}^{-1}$ more clearly illustrated the changes of functional group of MOF-818 before and after absorption. For the MOF-818 infrared spectroscopy, the band at $1675 \mathrm{~cm}^{-1}$ could be attributed to the $\mathrm{C}=\mathrm{O}$ stretching vibration of $-\mathrm{COOH}$, and the band at $1553 \mathrm{~cm}^{-1}$ to $\mathrm{C}=\mathrm{N}$ stretching vibration of pyrazole ring, respectively. The peaks at 1450 and $1294 \mathrm{~cm}^{-1}$ could be assigned to skeleton vibration of
Table 3 Thermodynamic parameter for the adsorption of TC on MOF-818

\begin{tabular}{lllllll}
\hline Antibiotic & \multicolumn{2}{l}{$\Delta G\left(\mathrm{~kJ} \mathrm{~mol}^{-1}\right)$} & & $\Delta H\left(\mathrm{~kJ} \mathrm{~mol}^{-1}\right)$ & $\Delta S\left(\mathrm{~kJ} \mathrm{~mol}^{-1}\right)$ \\
\cline { 2 - 5 } & $298 \mathrm{~K}$ & $303 \mathrm{~K}$ & $313 \mathrm{~K}$ & $323 \mathrm{~K}$ & & \\
\hline TC & -28.18 & -29.57 & -30.54 & -31.74 & 6.313 & 0.118 \\
\hline
\end{tabular}



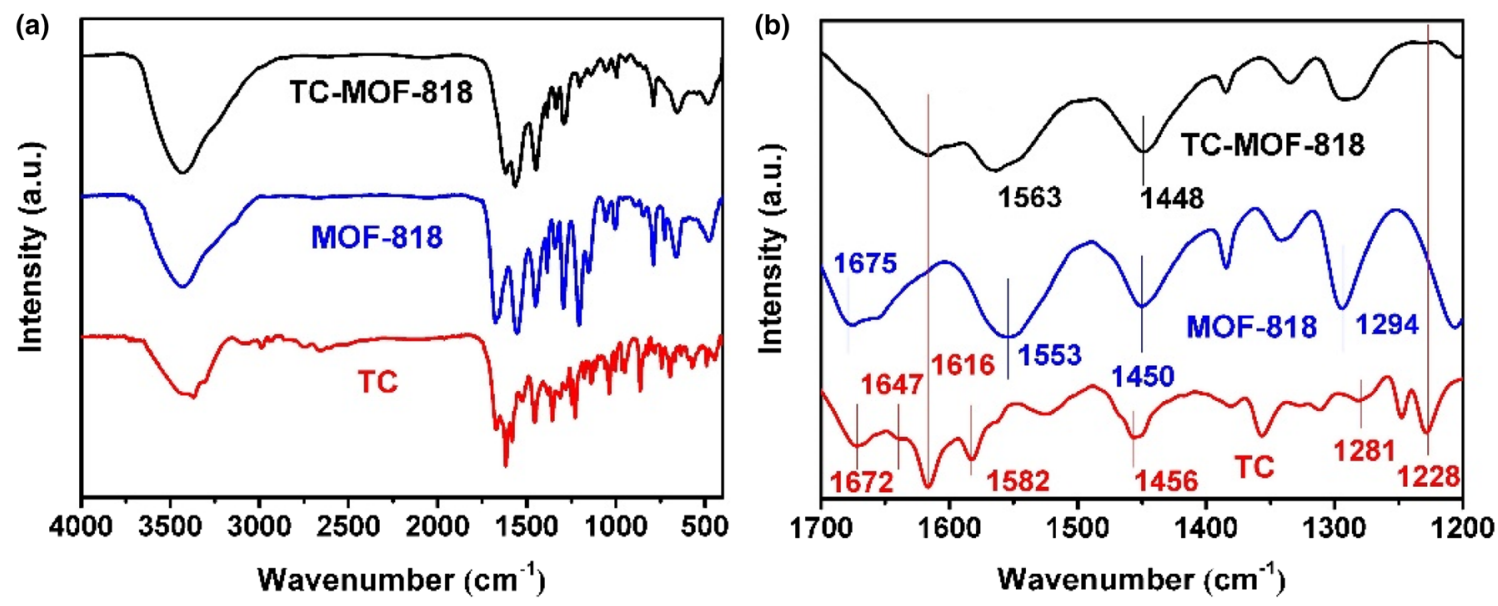

Fig. 6 FT-IR spectra: MOF-818, TC and TC-MOF-818

pyrazole ring and the $\mathrm{C}-\mathrm{N} / \mathrm{C}-\mathrm{O}$ stretching vibration. On the other hand, for the TC infrared spectroscopy, the vibration band at $1672 \mathrm{~cm}^{-1}, 1616 \mathrm{~cm}^{-1}$, and $1582 \mathrm{~cm}^{-1}$ could be assigned to amide I (the $\mathrm{C}=\mathrm{O}$ group of the $-\mathrm{CONH}_{2}$ ), the $\mathrm{C}=\mathrm{O}$ stretching at ring $A$ and $C=0$ group of ring $C$, respectively. The band at 1281 and $1228 \mathrm{~cm}^{-1}$ to the $\mathrm{N}-\mathrm{H}$ of amino and amide III (C-N bond of $-\mathrm{CONH}_{2}$ ) [54]. Compared with the FT-IR spectrum of MOF-818, the major infrared absorption peaks after adsorption (TC-MOF-818) were similar to that of MOF-818, with varying degrees of migration in wavenumber. Upon adsorption treatment, the peaks at $1616 \mathrm{~cm}^{-1}$ and $1228 \mathrm{~cm}^{-1}$ belong to TC molecules appeared on the FT-IR spectrum of TC-MOF-818, indicating that TC was adsorbed on the surface of MOF-818. However, the $\mathrm{C}=\mathrm{O}$ stretching peak at $1675 \mathrm{~cm}^{-1}$ was obviously weakened, and the $\mathrm{C}=\mathrm{N}$ stretching band at $1553 \mathrm{~cm}^{-1}$ was shifted to $1563 \mathrm{~cm}^{-1}$, which demonstrated the strong interaction between the functional groups of TC and MOF-818. Moreover, the skeleton vibration of pyrazole ring at $1450 \mathrm{~cm}^{-1}$ was migrated to $1448 \mathrm{~cm}^{-1}$. These changes could be ascribed to the $\pi-\pi$ conjugate effect caused by benzene ring, double bonds, amino and other functional groups which acted as $\pi$ electron donator or acceptor.

The chemical composition and electronic structure of various elements $(C, N, O, C u$ and $\mathrm{Zr}$ ) on the surface of MOF-818 and TC-MOF-818 were analyzed by XPS, respectively (Fig. 7). Both of MOF-818 and TC-MOF-818 showed the same spectrum with five main peaks, $\mathrm{Cu} 2 \mathrm{p}, \mathrm{O} 1 \mathrm{~s}, \mathrm{~N}$ $1 \mathrm{~s}, \mathrm{C} 1 \mathrm{~s}$ and $\mathrm{Zr} 3 \mathrm{~d}$ (Fig. 7a). The electron binding energy of $\mathrm{N}$ and $\mathrm{Zr}$ before and after absorption remained basically unchanged. However, electron binding energy of $\mathrm{C}$ and $\mathrm{Cu}$ were varied. As shown in Fig. 7b, the $C 1 \mathrm{~s}$ peaks of MOF818 at 284.5, 285.1, 285.9 and $290.4 \mathrm{eV}$ were assigned to $\mathrm{C}=\mathrm{C}, \mathrm{C}-\mathrm{C}, \mathrm{C}-\mathrm{N}$ (pyrazole ring) and $\mathrm{C}=\mathrm{O}$ (carboxyl), respectively. The peaks of TC-MOF-818 at 284.4, 285.0, 285.6 and $286.6 \mathrm{eV}$ were attributed to $\mathrm{C}=\mathrm{C}, \mathrm{C}-\mathrm{C}, \mathrm{C}-\mathrm{N}$ and $\mathrm{C}=\mathrm{O}(\mathrm{A}, \mathrm{C}$ ring from TC). Comparatively, the peak for $\mathrm{C}=\mathrm{O}$ (carboxyl) was weakened after adsorption, while the peak for $C=O$ ( $A, C$ ring from TC) appeared, revealing the strong interaction between carboxyl of MOF- 818 and TC molecules. In
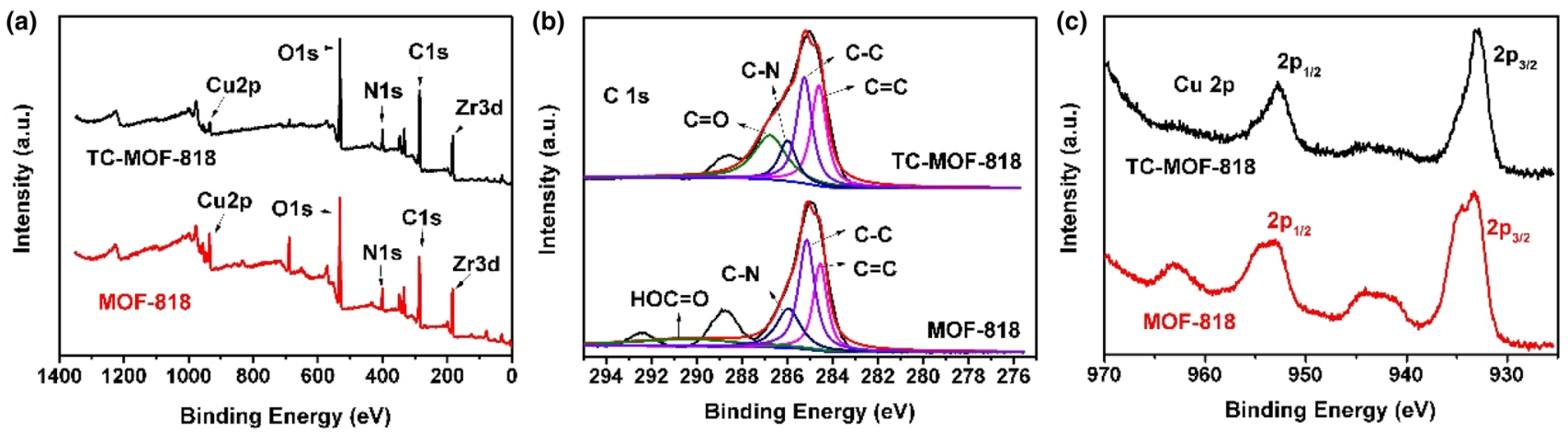

Fig. 7 XPS spectra: MOF-818 and TC-MOF-818 
addition, it is observed that the peak of $\mathrm{C}-\mathrm{N}$ was shifted from 285.9 to $285.6 \mathrm{eV}$ after TC adsorbed onto MOF-818, suggesting that some chemical reaction occurred. These results were well consistent with FT-IR analysis. On the other hand, $\mathrm{Cu}^{2+}$ was a coordination metal with $\mathrm{N}$ on $\mathrm{H}_{2} \mathrm{PyC}$ in MOF-818 structure. Whereas the $\mathrm{Cu} 2 \mathrm{p}$ spectrum exhibited two contributions $2 p_{3 / 2}$ and $2 p_{1 / 2}$, and the characteristic peak $2 p_{3 / 2}$ was shifted from 933.5 to $932.9 \mathrm{eV}$ after adsorption (Fig. 7c), indicating that $\mathrm{Cu}^{2+}$ was involved in chemisorption. The new coordinate bond between $\mathrm{Cu}^{2+}$ and $\mathrm{O}, \mathrm{N}$ from TC might be formed.

Based on the above analysis, we speculated that multiple mechanisms and various interactions would be involved in the whole TC adsorption process. At first, the pore-filling by partition effect is one of the mechanisms that influencing the adsorption process. The MOF-818 would be considered as a tailor-made adsorbent for TC removal, since its ultra-high porosity and mesoporous might benefit the mass transfer process of the adsorbate and enhance adsorption. On the other hand, the capture of organic-based toxins relies primarily on noncovalent interactions including $\pi-\pi$ interactions, van der Waals interactions, hydrophobic interactions. We believed these interactions were also existed between TC and MOF-818. Moreover, $\mathrm{Cu}^{2+}$ was involved in chemisorption and the new coordinate bond between $\mathrm{Cu}^{2+}$ and $\mathrm{O}, \mathrm{N}$ from TC might be formed. However, because of the strong interaction between TC molecules and MOF-818, we found that the absorbed TC molecules were not easy to desorb from MOF- 818 by soaking with ethanol, DMF, THF, acetone, sodium hydroxide solution, hydrochloric acid solution, and so on. Further research for its recovery and recycling performance is still being explored. Even so, this research provides the underlying insights to guide the design of promising adsorbent for antibiotics removal.

\section{Conclusions}

In the present study, mesoporous cage MOF-818 was synthesized successfully and confirmed by XRD, BET, SEM, TGA, FT-IR and XPS. The synthesized samples were successfully utilized for the removal of tetracycline hydrochloride (TC) from aqueous environment. Batch experiments were systematically conducted to reveal the adsorption process by varying solution $\mathrm{pH}$, contact time, temperature, adsorption dosage, initial TC concentration. The adsorption process accorded well with the Langmuir model, indicating that the antibiotic adsorption occurred on MOF-818 as an adsorbent monolayer. The kinetics data was found to be fitted by the pseudo-second-order kinetic model. Thermodynamic studies showed that adsorption was endothermic and spontaneous. The intra-particle diffusion model proved that the overall adsorption process of TC onto MOF-818 was controlled by outer diffusion and intra-partical diffusion. The maximum saturated adsorption capacity of TC on MOF-818 was calculated to be $442.5 \mathrm{mg} \mathrm{g}^{-1}$, showing highly efficient adsorption. It was observed that enhanced adsorption property of MOF-818 was ascribed to the $\pi-\pi$ interaction and the chemisorption between TC and MOF-818.

Acknowledgements This work was supported financially by the National Natural Science Foundation of China (Grant No. 21777149) and Opening Project of Engineering Research Center of Nano-Geo Materials of Ministry of Education of China University of Geosciences (NGM2020KF015).

\section{Compliance with ethical standards}

Conflict of interest There are no conflicts to declare.

\section{References}

1. Sahu S, Sahu UK, Patel PK (2018) Synthesis of thorium-ethanolamine nanocomposite by the co-precipitation method and its application for $\mathrm{Cr}(\mathrm{VI})$ removal. New J Chem 42:5556-5569. https ://doi.org/10.1039/c7nj05074g

2. Sahu S, Kar P, Bishoyi N, Mallik NL, Patel RK (2019) Synthesis of polypyrrole-modified layered double hydroxides for efficient removal of $\mathrm{Cr}(\mathrm{VI})$. J Chem Eng Data 64:4357-4368. https://doi. org/10.1021/acs.jced.9b00444

3. Sahu S, Sahu UK, Patel RK (2019) Modified thorium oxide polyaniline core-shell nanocomposite and its application for the efficient removal of $\mathrm{Cr}(\mathrm{VI})$. J Chem Eng Data 64:1294-1304. https:// doi.org/10.1021/acs.jced.8b01225

4. Sahu UK, Sahu S, Mahapatra SS, Patel RK (2017) Cigarette soot activated carbon modified with $\mathrm{Fe}_{3} \mathrm{O}_{4}$ nanoparticles as an effective adsorbent for $\mathrm{As}(\mathrm{III})$ and $\mathrm{As}(\mathrm{V})$ : material preparation, characterization and adsorption mechanism study. J Mol Liq 243:395-405. https://doi.org/10.1016/j.molliq.2017.08.055

5. Sahu UK, Sahu S, Mahapatra SS, Patel RK (2018) Synthesis and characterization of magnetic bio-adsorbent developed from Aegle marmelos leaves for removal of $\mathrm{As}(\mathrm{V})$ from aqueous solutions. Environ Sci Pollut R 26:946-958. https://doi.org/10.1007/ s11356-018-3643-1

6. Naushad M, Alothman ZA, Awual MR, Alam MM, Eldesoky GE (2015) Adsorption kinetics, isotherms, and thermodynamic studies for the adsorption of $\mathrm{Pb}^{2+}$ and $\mathrm{Hg}^{2+}$ metal ions from aqueous medium using Ti(IV) iodovanadate cation exchanger. lonics 21:2237-2245. https://doi.org/10.1007/s11581-015-1401-7

7. Naushad M, Alothman ZA (2013) Separation of toxic $\mathrm{Pb}^{2+}$ metal from aqueous solution using strongly acidic cation-exchange resin: analytical applications for the removal of metal ions from pharmaceutical formulation. Desalin Water Treat 53:2158-2166. https://doi.org/10.1080/19443994.2013.862744

8. Alqadami AA, Naushad M, Abdalla MA, Khan MR, Alothman ZA (2016) Adsorptive removal of toxic dye using $\mathrm{Fe}_{3} \mathrm{O}_{4}-\mathrm{TSC}$ nanocomposite: equilibrium, kinetic, and thermodynamic studies. J Chem Eng Data. 61:3806-3813

9. Naushad M, Alqadami AA, AlOthman ZA, Alsohaimi IH, Algamdi MS, Aldawsari AM (2019) Adsorption kinetics, isotherm and reusability studies for the removal of cationic dye from aqueous 
medium using arginine modified activated carbon. J Mol Liq 293:111442. https://doi.org/10.1016/j.molliq.2019.111442

10. Alqadami AA, Naushad M, Alothman ZA, Ahamad T (2018) Adsorptive performance of MOF nanocomposite for methylene blue and malachite green dyes: kinetics, isotherm and mechanism. J Environ Manag 223:29-36. https://doi.org/10.1016/j. jenvman.2018.05.090

11. Sharma G, Kumar A, Naushad M, Kumar A, Al-Muhtaseb AAH, Dhiman P, Ghfar AA, Stadler FJ, Khan MR (2018) Photoremediation of toxic dye from aqueous environment using monometallic and bimetallic quantum dots based nanocomposites. J Clean Prod 172:2919-2930. https://doi.org/10.1016/j.jclep ro.2017.11.122

12. Naushad M, Sharma G, Alothman ZA (2019) Photodegradation of toxic dye using Gum Arabic-crosslinked-poly(acrylamide)/ $\mathrm{Ni}(\mathrm{OH})_{2} / \mathrm{FeOOH}$ nanocomposites hydrogel. J Clean Prod 241:118263. https://doi.org/10.1016/j.jclepro.2019.118263

13. Nair RR, Demarche P, Agathos SN (2013) Formulation and characterization of an immobilized laccase biocatalyst and its application to eliminate organic micropollutants in wastewater. New Biotechnol 30:814-823. https://doi.org/10.1016/j. nbt.2012.12.004

14. Ocampo-Pérez R, Rivera-Utrilla J, Gómez-Pacheco C, SánchezPolo M, López-Peñalver JJ (2012) Kinetic study of tetracycline adsorption on sludge-derived adsorbents in aqueous phase. Chem Eng J 213:88-96. https://doi.org/10.1016/j. cej.2012.09.072

15. Daghrir R, Drogui $P$ (2013) Tetracycline antibiotics in the environment: a review. Environ Chem Lett 11:209-227. https://doi. org/10.1007/s10311-013-0404-8

16. Hao R, Xiao X, Zuo X, Nan J, Zhang W (2012) Efficient adsorption and visible-light photocatalytic degradation of tetracycline hydrochloride using mesoporous $\mathrm{BiOl}$ microspheres. J Hazard Mater 209-210:137-145. https://doi.org/10.1016/j.jhazm at.2012.01.006

17. Niu J, Xie Y, Luo H, Wang Q, Zhang Y, Wang Y (2019) Cobalt oxide loaded graphitic carbon nitride as adsorptive photocatalyst for tetracycline removal from aqueous solution. Chemosphere 218:169-178. https://doi.org/10.1016/j.chemospher e.2018.11.111

18. Gómez-Pacheco CV, Sánchez-Polo M, Rivera-Utrilla J, LópezPeñalver J (2011) Tetracycline removal from waters by integrated technologies based on ozonation and biodegradation. Chem Eng J 178:115-121. https://doi.org/10.1016/j.cej.2011.10.023

19. Chang PH, Jean JS, Jiang WT, Li Z (2009) Mechanism of tetracycline sorption on rectorite. Colloid Surf A 339:94-99. https://doi. org/10.1016/j.colsurfa.2009.02.002

20. Chang PH, Li Z, Yu TL, Munkhbayer S, Kuo TH, Hung YC, Jean JS, Lin KH (2009) Sorptive removal of tetracycline from water by palygorskite. J Hazard Mater 165:148-155. https://doi. org/10.1016/j.jhazmat.2008.09.113

21. Wan D, Wu L, Liu Y, Chen J, Zhao H, Xiao S (2019) Enhanced adsorption of aqueous tetracycline hydrochloride on renewable porous clay-carbon adsorbent derived from spent bleaching earth via pyrolysis. Langmuir 35:3925-3936. https://doi. org/10.1021/acs.langmuir.8b04179

22. Liu M, An D, Hou L, Yu S, Zhu Y (2015) Zero valent iron particles impregnated zeolite $X$ composites for adsorption of tetracycline in aquatic environment. RSC Adv 5:103480-103487. https://doi. org/10.1039/c5ra21715f

23. Guo Y, Huang W, Chen B, Zhao Y, Liu D, Sun Y, Gong B (2017) Removal of tetracycline from aqueous solution by MCM-41-zeolite A loaded nano zero valent iron: synthesis, characteristic, adsorption performance and mechanism. J Hazard Mater 339:22-32. https://doi.org/10.1016/j.jhazmat.2017.06.006
24. Gao Y, Li Y, Zhang L, Huang H, Hu J, Shah SM, Su X (2012) Adsorption and removal of tetracycline antibiotics from aqueous solution by graphene oxide. J Colloid Interf Sci 368:540-546. https ://doi.org/10.1016/j.jcis.2011.11.015

25. Zhang L, Song X, Liu X, Yang L, Pan F, Lv J (2011) Studies on the removal of tetracycline by multi-walled carbon nanotubes. Chem Eng J 178:26-33. https://doi.org/10.1016/j. cej.2011.09.127

26. Jang HM, Kan E (2019) Engineered biochar from agricultural waste for removal of tetracycline in water. Bioresour Technol 284:437-447. https://doi.org/10.1016/j.biortech.2019.03.131

27. Jang HM, Kan E (2019) A novel hay-derived biochar for removal of tetracyclines in water. Bioresour Technol 274:162-172. https ://doi.org/10.1016/j.biortech.2018.11.081

28. Zeng Z, Ye S, Wu H, Xiao R, Zeng G, Liang J, Zhang C, Yu J, Fang $Y$, Song B (2019) Research on the sustainable efficacy of g-MoS2 decorated biochar nanocomposites for removing tetracycline hydrochloride from antibiotic-polluted aqueous solution. Sci Total Environ 648:206-217. https://doi.org/10.1016/j.scito tenv.2018.08.108

29. Nguyen VT, Nguyen TB, Chen CW, Hung CM, Vo TD, Chang JH, Dong CD (2019) Influence of pyrolysis temperature on polycyclic aromatic hydrocarbons production and tetracycline adsorption behavior of biochar derived from spent coffee ground. Bioresour Technol 284:197-203. https://doi.org/10.1016/j.biort ech.2019.03.096

30. Li H, Hu J, Meng Y, Su J, Wang X (2017) An investigation into the rapid removal of tetracycline using multilayered graphene-phase biochar derived from waste chicken feather. Sci Total Environ 603-604:39-48. https://doi.org/10.1016/j.scito tenv.2017.06.006

31. Guan X, Li H, Ma Y, Xue M, Fang Q, Yan Y, Valtchev V, Qiu S (2019) Chemically stable polyarylether-based covalent organic frameworks. Nat Chem 11:587-594. https://doi.org/10.1038/s4155 7-019-0238-5

32. Wang C, Xu W, Ren YN, Zhu HL, Zheng YQ (2019) Removal of tetracycline hydrochloride from aqueous solution by three 3D uranyl-organic frameworks. Inorg Chim Acta 493:29-37. https ://doi.org/10.1016/j.ica.2019.04.046

33. Li N, Zhou L, Jin X, Owens G, Chen Z (2019) Simultaneous removal of tetracycline and oxytetracycline antibiotics from wastewater using a ZIF-8 metal organic-framework. J Hazard Mater 366:563-572. https://doi.org/10.1016/j.jhazm at.2018.12.047

34. Zhou Y, Yang Q, Zhang D, Gan N, Li Q, Cuan J (2018) Detection and removal of antibiotic tetracycline in water with a highly stable luminescent MOF. Sens Actuator B Chem 262:137-143. https ://doi.org/10.1016/j.snb.2018.01.218

35. Chen X, Jiang X, Yin C, Zhang B, Zhang Q (2019) Facile fabrication of hierarchical porous ZIF-8 for enhanced adsorption of antibiotics. J Hazard Mater 367:194-204. https://doi.org/10.1016/j.jhazm at.2018.12.080

36. Dehghan A, Zarei A, Jaafari J, Shams M, Khaneghah AM (2019) Tetracycline removal from aqueous solutions using zeolitic imidazolate frameworks with different morphologies: a mathematical modeling. Chemosphere 217:250-260. https://doi. org/10.1016/j.chemosphere.2018.10.166

37. Yang W, Han Y, Li C, Zhu L, Shi L, Tang W, Wang J, Yue T, Li Z (2019) Shapeable three-dimensional CMC aerogels decorated with $\mathrm{Ni} /$ Co-MOF for rapid and highly efficient tetracycline hydrochloride removal. Chem Eng J 375:122076. https://doi.org/10.1016/j. cej.2019.122076

38. Yang Z, Cao J, Chen Y, Li X, Xiong W, Zhou Y, Zhou C, Xu R, Zhang $Y$ (2019) Mn-doped zirconium metal-organic framework as an effective adsorbent for removal of tetracycline and $\mathrm{Cr}(\mathrm{VI})$ from 
aqueous solution. Microporous Mesoporous Mater 277:277285. https://doi.org/10.1016/j.micromeso.2018.11.014

39. Xiong W, Zeng G, Yang Z, Zhou Y, Zhang C, Cheng M, Liu Y, Hu L, Wan J, Zhou C, Xu R, Li X (2018) Adsorption of tetracycline antibiotics from aqueous solutions on nanocomposite multi-walled carbon nanotube functionalized MIL-53(Fe) as new adsorbent. Sci Total Environ 627:235-244. https://doi.org/10.1016/j.scito tenv.2018.01.249

40. Xiong W, Zeng Z, Li X, Zeng G, Xiao R, Yang Z, Zhou Y, Zhang C, Cheng M, Hu L, Zhou C, Qin L, Xu R, Zhang Y (2018) Multiwalled carbon nanotube/amino-functionalized MIL-53(Fe) composites: remarkable adsorptive removal of antibiotics from aqueous solutions. Chemosphere 210:1061-1069. https://doi. org/10.1016/j.chemosphere.2018.07.084

41. Yu LL, Cao W, Wu SC, Yang C, Cheng JH (2018) Removal of tetracycline from aqueous solution by MOF/graphite oxide pellets: preparation, characteristic, adsorption performance and mechanism. Ecotoxicol Environ Saf 164:289-296. https://doi. org/10.1016/j.ecoenv.2018.07.110

42. Liu H, Chen L, Ding J (2017) A core-shell magnetic metal organic framework of type $\mathrm{Fe}_{3} \mathrm{O}_{4} @ \mathrm{ZIF}-8$ for the extraction of tetracycline antibiotics from water samples followed by ultra-HPLC-MS analysis. Microchim Acta 184:4091-4098. https://doi.org/10.1007/ s00604-017-2442-6

43. Jin J, Yang Z, Xiong W, Zhou Y, Xu R, Zhang Y, Cao J, Li X, Zhou C (2019) Cu and Co nanoparticles co-doped MIL-101 as a novel adsorbent for efficient removal of tetracycline from aqueous solutions. Sci Total Environ 650:408-418. https://doi. org/10.1016/j.scitotenv.2018.08.434

44. Wu C, Xiong Z, Li C, Zhang J (2015) Zeolitic imidazolate metal organic framework ZIF-8 with ultra-high adsorption capacity bound tetracycline in aqueous solution. RSC Adv 5:8212782137. https://doi.org/10.1039/c5ra15497a

45. Chao S, Li X, Li Y, Wang Y, Wang C (2019) Preparation of polydopamine-modified zeolitic imidazolate framework-8 functionalized electrospun fibers for efficient removal of tetracycline. $J$ Colloid Interface Sci 552:506-516. https://doi.org/10.1016/j. jcis.2019.05.078

46. Zhu X, Li C, Li J, Xie B, Lu J, Li Y (2018) Thermal treatment of biochar in the air/nitrogen atmosphere for developed mesoporosity and enhanced adsorption to tetracycline. Bioresour Technol 263:475-482. https://doi.org/10.1016/j.biortech.2018.05.041
47. Li S, Lu J, Zhang T, Cao Y, Li J (2017) Relationship between biochars' porosity and adsorption of three neutral herbicides from water. Water Sci Technol 75:482-489. https://doi.org/10.2166/ wst.2016.535

48. Zhang M, Li A, Zhou Q, Shuang C, Zhou W, Wang M (2014) Effect of pore size distribution on tetracycline adsorption using magnetic hypercrosslinked resins. Microporous Mesoporous Mater 184:105-111. https://doi.org/10.1016/j.micromeso.2013.10.010

49. Li C, Zhu X, He H, Fang Y, Dong H, Lü J, Li J, Li Y (2019) Adsorption of two antibiotics on biochar prepared in air-containing atmosphere: influence of biochar porosity and molecular size of antibiotics. J MoL Liq 274:353-361. https://doi.org/10.1016/j. molliq.2018.10.142

50. Liu Q, Song Y, Ma Y, Zhou Y, Cong H, Wang C, Wu J, Hu G, O'Keeffe $M$, Deng H (2019) Mesoporous cages in chemically robust MOFs created by a large number of vertices with reduced connectivity. J Am Chem 141:488-496. https://doi.org/10.1021/jacs.8b11230

51. Qiu H, Lv L, Pan BC, Zhang QJ, Zhang WM, Zhang QX (2009) Critical review in adsorption kinetic models. J Zhejiang Univ Sci A 10:716-724. https://doi.org/10.1631/jzus.A0820524

52. Mironyuk I, Tatarchuk T, Naushad M, Vasylyeva H, Mykytyn I (2019) Highly efficient adsorption of strontium ions by carbonated mesoporous $\mathrm{TiO}_{2}$. J Mol Liq 285:742-753. https://doi. org/10.1016/j.molliq.2019.04.111

53. Zhao G, Li J, Wang X (2011) Kinetic and thermodynamic study of 1-naphthol adsorption from aqueous solution to sulfonated graphene nanosheets. Chem Eng J 173:185-190. https://doi. org/10.1016/j.cej.2011.07.072

54. Antón-Herrero R, García-Delgado C, Alonso-Izquierdo G, GarcíaRodríguez G, Cuevas J, Eymar E (2018) Comparative adsorption of tetracyclines on biochars and stevensite: looking for the most effective adsorbent. Appl Clay Sci 160:162-172. https:// doi.org/10.1016/j.clay.2017.12.023

Publisher's Note Springer Nature remains neutral with regard to jurisdictional claims in published maps and institutional affiliations. 